\title{
Experiencias en la transferencia tecnológica del proyecto de Cafés Especiales
}

\section{Experiences in the technology transfer of the Specialty Coffee Project}

\section{María Paula Acosta-Andrade ${ }^{1}$ Julián Ávila-Navarro²}

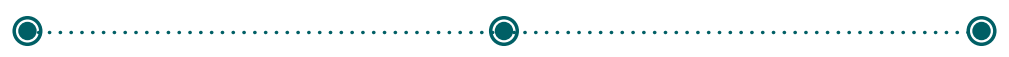

Recepción: 28/09/2021 Aprobación: 07/12/2021 Publicación: 22/12/2021

Para citar este artículo Acosta-Andrade, M. P., \& Ávila-Navarro, J. (2021). Experiencias en la transferencia tecnológica del proyecto de Cafés Especiales. Indagare, (9), 81-87. https://doi.org/10.35707/indagare/908

\footnotetext{
' Grupo de investigación EULOGOS, Universidad de Ibagué, Ibagué, Colombia. ORCID: 0000-0002-2287-1750. Correo electrónico: maria.acosta@unibague.edu.co

2 Grupo de investigación GMAE, Universidad de Ibagué, Ibagué, Colombia. ORCID: 0000-0001-5675-6104.

Correo electrónico: julian.avila@unibague.edu.co
} 


\section{Resumen}

El proyecto de Cafés Especiales de la Universidad de Ibagué, la Universidad del Tolima y la Gobernación del Tolima es un proyecto que ha beneficiado a un grupo de familias cafeteras de la región del Tolima con tecnologías ecológicas para el mejoramiento de sus procesos de poscosecha de café mediante el uso de biodigestores. El propósito de este artículo es mostrar y analizar las experiencias de transferencia tecnológica de los integrantes del proyecto, desde una perspectiva técnica y social, encontrando que las comunidades cafeteras estaban dispuestas a cambiar y a aprender nuevas tecnologías que pudieran aumentar su calidad de vida y el valor agregado de su café.

\section{Abstract}

The Specialty Coffee project of Universidad de Ibagué, Universidad del Tolima and the Government of Tolima is a project that has benefited a group of coffee-growing families in the Tolima region with ecological technologies for the improvement of their coffee post-harvest processes through the use of biodigesters. The aim of this article is to show and analyze the technology transfer experiences of the members of the project, from a technical and social perspective, finding that coffee communities were willing to change and learn new technologies that could increase their quality of life and the added value of their coffee.

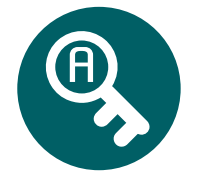

Palabras claves: Transferencia tecnológica, caficultores, cafés especiales, innovación, academia.

Key words: Technology transfer, coffee growers, specialty coffee, innovation, academy.

\section{Introducción}

El café es el principal renglón agrícola del Tolima en términos de área sembrada, empleo generado y contribución a las exportaciones, y representa el 68 \% de la población rural. En volumen de producción a escala nacional, el Departamento ocupa el tercer lugar, con una participación de $12 \%$, después de Huila y Antioquia (Federación Nacional de Cafeteros de Colombia, 2019). Esto hace que el Tolima sea uno de los representantes en la producción de café, entendiendo, además, los retos que enfrenta el sector agrícola, especialmente los cafeteros independientes o con asociaciones no empresariales, quienes no cuentan con la facilidad de recursos en sus organizaciones o se encuentran en proceso de transición hacia nuevas tecnologías y que, según la Federación Nacional 
de Cafeteros (Federación Nacional de Cafeteros de Colombia, 2020), pueden presentar mayores dificultades en la asimetría de la información, conocimiento en costos o falta de innovación.

Así bien, el proyecto de Cafés Especiales del Tolima involucró a miembros de la academia y entes gubernamentales, que buscaron innovar los procesos a nivel de postcosecha para la incorporación de valor agregado, con el propósito de alcanzar a 551 familias de 13 municipios del Departamento y mejorar la calidad del producto orgánico (El Nuevo Día, 2021). Estos procesos de innovación fueron relacionados al uso de tecnologías en energías renovables, basados en la implementación de biodigestores para realizar el secado de café asistido por biogás. Este sistema les permitió a los caficultores aprovechar los residuos orgánicos generados por los animales de sus fincas, como también los generados en el proceso de beneficio del café (aguas mieles), para la generación de biogás que, por medio de un sistema térmico, fue usado para el secado del café en marquesinas (Hernández-Sarabia, Sierra-Silva, Delgadillo-Mirquez, Ávila-Navarro, \& Carranza, 2021).

Teniendo en cuenta todos estos beneficios tecnológicos, surgió uno de los retos más importantes del proyecto y fue realizar la transferencia tecnológica a los caficultores, para que pudieran apropiar estos sistemas en su cotidianidad, entenderlos y reconocer la importancia y beneficio de estos. En este artículo se pretende analizar las experiencias del proceso de transferencia tecnológica en las diferentes etapas realizadas por el proyecto de Cafés Especiales, mediante la recopilación de testimonios de los investigadores involucrados en este proceso, búsqueda de documentación y demás.

\section{Instalación del biodigestor}

La función principal de los biodigestores rurales es capturar las emisiones biogás (metano + dióxido de carbono), producidas por la fermentación de la materia orgánica obtenida de las actividades agrícolas (estiércol, residuos alimenticios, aguas mieles del café). De este modo, es posible aprovechar estos residuos como fuente de energía y minimizar la contribución de los gases de efecto invernadero en el medio ambiente (Hernández-Sarabia, et al., 2021). Para lograr un buen resultado en la producción de biogás es necesaria una correcta instalación del biodigestor. Uno de los grandes desafíos técnicos del proyecto fue dicha instalación, debido a que cada finca contaba con una disposición geográfica diferente, lo cual cambiaba, para cada caso, las dimensiones de la tubería, conexiones y cantidad de material requerido para llevar la salida de biogás tanto a la cocina de la finca, como a la marquesina para el secado de café. en la Figura 1 se aprecia el proceso de instalación del biodigestor implementado en Dolores, Tolima. 


\section{Aprovechamiento del biogás}

Los procesos de postcosecha del café están principalmente compuestos por dos etapas: el beneficio del café y el secado. En el proceso de beneficiado del café se realiza la fermentación y lavado de la semilla, en este proceso se obtiene como residuo las aguas mieles del café, las cuales son altamente contaminantes en suelos y cuerpos hídricos. En este caso, las aguas mieles de café presentan un alto potencial para ser usadas como sustrato para el biodigestor, siendo reutilizadas en forma de biogás (Chinappi Ciccolella \& Jerez Carrizo, 2008). En cuanto al proceso de secado del café, el proyecto contempló el uso del biogás generado por los biodigestores para ser pasado por un intercambiador de calor que, con la quema del biogás, es capaz de generar una corriente de aire caliente que es ingresado a la marquesina, garantizando temperaturas de 40 a $45^{\circ} \mathrm{C}$, óptimas para el secado del grano de café (Hernández-Sarabia et al., 2021).

\section{Análisis}

Bajo la firma de un consentimiento informado, se realizaron y transcribieron las entrevistas de dos miembros de la Universidad de Ibagué, representantes del proyecto de Cafés Especiales y con base a ellas se hizo un breve análisis con la herramienta Atlas. Ti 8, la cual, desde un enfoque cualitativo, permite categorizar las experiencias (Varguillas, 2006). Lo anterior, con el fin de conocer la visión de los implicados acerca del proyecto y su perspectiva de los caficultores en la transferencia tecnológica con los biodigestores. Por lo que se obtuvo que el mayor índice de referencia son los Caficultores, mencionados 37 veces, siendo estos el tema principal, seguidos del índice de Proceso, mencionado 19 veces a lo largo de las entrevistas, lo que puede dar a entender, según la visión de los miembros del proyecto participantes, que los caficultores indicaron una mejoría en el proceso de poscosecha gracias al uso del biodigestor, como lo muestra la Figura 2.

Figura 2. Nube de palabras experiencias miembros de la Universidad de Ibagué

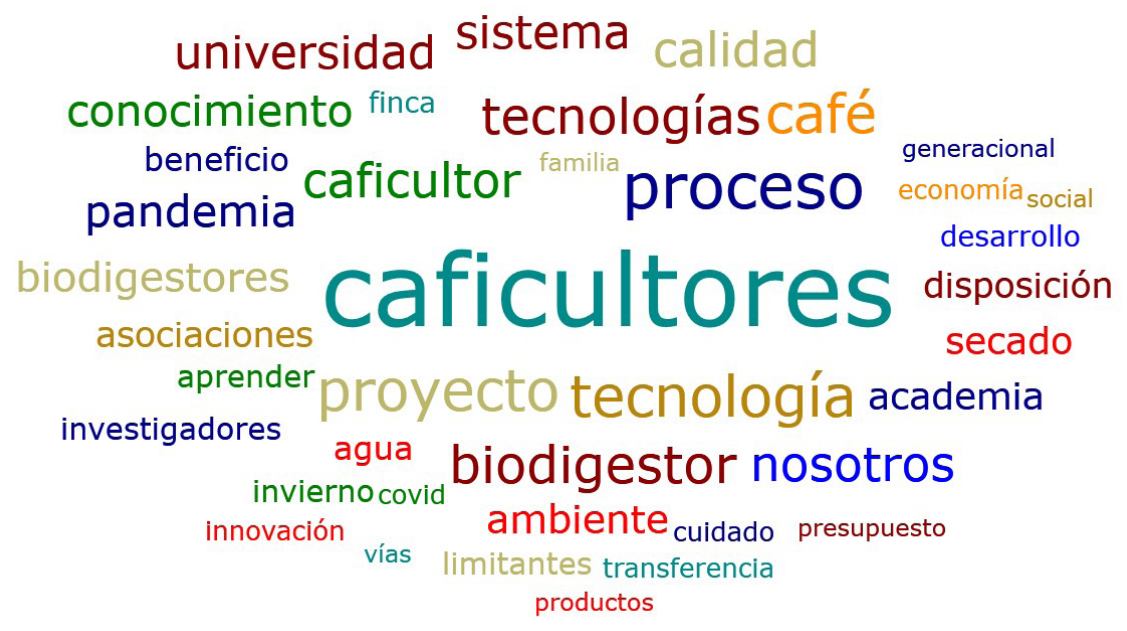

Fuente: Elaboración propia 
Para el momento del análisis de contenido hermenéutico se crearon las categorías de: Desarrollo de transferencia tecnológica, la cual se dividió en las subcategorías apropiación del conocimiento (la cual contó con 13 citas), aceptación por parte de los caficultores (con 7 citas) y seguimiento (con 4 citas). Las limitantes en la transferencia, donde sobresalen limitantes situacionales (con 11 citas), culturales (con 10 citas), y físicas (con 8 citas). Y los aportes a la transferencia, enfocando aportes sociales (con 15 citas), ambientales (con 11 citas), y económicos (con 10 citas).

Las citas más representativas a partir de las experiencias obtenidas en cada categoría son: la apropiación del conocimiento en la categoría de transferencia tecnológica, como se puede evidenciar en "tenemos mucho como academia para aportar al sector agrícola" (Agredo, Entrevista, 2021). Las limitaciones situacionales en la categoría de limitantes en la transferencia de conocimiento, como se puede evidenciar en "la pandemia nos cambió la forma de ver y hacer las cosas" (Agredo, Entrevista, 2021). Y los aportes sociales en la categoría de aportes a la transferencia, como se muestra en "el mejor aporte es que ellos cuidan mucho más su producto [...]” (Hernández, Entrevista, 2021).

\section{Conclusión}

La información analizada de las dos entrevistas permite identificar los factores que generaron mayor impacto en la transferencia tecnológica, tanto de los caficultores como de los miembros académicos, quienes superaron las dificultades físicas, de acceso y situacionales, como la pandemia, logrando dar un valor agregado a los productos de las familias caficultoras al incluir energías renovables en sus procesos y, a su vez, contribuir a la mejora en su calidad de vida, mediante el uso del biogás en la cocción de los alimentos y el aprovechamiento de las aguas del café mieles como sustrato para los biodigestores, las cuales son usualmente vertidas en los ríos.

Se hizo énfasis en la posible importancia de la edad al referirse que "el empalme generacional puede llegar a tener una percepción diferente" (Agredo, Entrevista, 2021). O, "a veces la edad hace que sean más reacios al cambio [...]" (Agredo, Entrevista, 2021). Estas percepciones pueden hacer reflexionar sobre la forma en que afectan los factores sociodemográficos y psicológicos a los procesos de innovación como lo fue el uso del biodigestor, además de preguntarse: ¿Cómo incentivar a los jóvenes de la academia a interesarse por el sector agrícola?

Finalizado el proyecto, se entiende que la apropiación del conocimiento por parte de los caficultores y el impacto social fue acorde a los resultados esperados, por lo que se sugiere involucrar a miembros de la comunidad y otro tipo de profesionales que estudien otra clase de factores que influyen en el proceso y en las necesidades de los 
caficultores del Tolima, para extender y replicar este proceso en más familias cafeteras de la región.

\section{Referencias}

Chinappi Ciccolella, I., \& Jerez Carrizo, A. (2008). Biodigestión anaeróbica de la pulpa de café. Propuesta de saneamiento ambiental y ahorro energético. Revista Academia, 13(13), 75-83. Recuperado de http://epublica.saber.ula.ve/index.php/academia/article/view/6031/5832

El Nuevo Día. (16 de julio de 2021). Cafés Especiales, proyecto que cruza las fronteras del Tolima. El Nuevo Día. Recuperado de https://www.elnuevodia.com.co/nuevodia/especiales/generales/470675-cafes-especiales-proyecto-que-cruza-las-fronteras-del-tolima

Federación Nacional de Cafeteros. (2020). Ensayos sobre Economía Cafetera (n. $\left.{ }^{\circ} 33\right)$. Recuperado de https://federaciondecafeteros.org/app/uploads/2020/05/Economía-Cafetera-No.-33-Web-mayo-30.pdf

Federación Nacional de Cafeteros de Colombia. (2019). Informe de Gestión 2019. Recuperado de https://cdn.flipsnack.com/widget/v2/widget.html?hash=dpazs597t9

Hernández-Sarabia, M., Sierra-Silva, J., Delgadillo-Mirquez, L., Ávila-Navarro, J., \& Carranza, L. (2021). The Potential of the Biodigester as a Useful Tool in Coffee Farms. Applied Sciences 2021, 11(15), 6884. https://doi.org/10.3390/APP11156884

Varguillas, C. (2006). El uso de atlas.Ti y la creatividad del investigador en el análisis cualitativo de contenido. Laurus, 12, 73-87. Recuperado de https://www.redalyc.org/articulo.oa?id=76109905 